\title{
Contextualizando as Atividades Desplugadas para Aumentar o Engajamento das Crianças
}

\author{
Soraya R. S. Medeiros ${ }^{1}$, Cibelle A. Martins ${ }^{1}$, Charles A. G. Madeira ${ }^{1}$ \\ ${ }^{1}$ Programa de Pós-graduação em Inovação em Tecnologias Educacionais (PpgITE) - \\ Instituto Metrópole Digital (IMD) - Universidade Federal do Rio Grande do Norte \\ (UFRN) - Natal, RN-Brasil \\ soraya_rb@ufrn.edu.br, cibelle.amorim@ce.ufrn.br, charleseimd.ufrn.br
}

\begin{abstract}
SARS-CoV-2 pandemic has deprived children from their school activities, forcing parents to seek alternatives so that kids develop new skills. Unplugged computing is proving to be a good option, but in order to engage children, activities need to be contextualised with their everyday lives. This work introduces a model for making unplugged activities in a contextualized way. The model was used for developing a Computational Thinking Guide for 6 to 11 years old children that was validated using Participatory Design. As results, activities were well evaluated and the need for more illustrations was highlighted.
\end{abstract}

Resumo. A pandemia do vírus Sars-Cov-2 privou as crianças das suas atividades escolares, o que forçou os pais a buscarem alternativas para que elas desenvolvam novas habilidades. A computação desplugada se mostra como uma boa opção, mas, para que haja engajamento das crianças, é preciso que as atividades sejam contextualizadas com o seu dia a dia. $O$ presente trabalho introduz um modelo para construção de atividades desplugadas contextualizadas. Esse modelo foi experimentado no desenvolvimento de um Guia do Pensamento Computacional para crianças de 6 a 11 anos, que foi validado por meio do Design Participativo. Como resultados, as atividades foram bem avaliadas e evidenciaram a necessidade de haver mais ilustrações.

\section{Introdução}

O Pensamento Computacional (PC) é compreendido como um conjunto de técnicas da Computação aplicado à resolução de problemas cotidianos, sendo tão importante quanto saber ler e efetuar cálculos matemáticos [Wing 2006]. Por causa disso, desenvolver o Pensamento Computacional é diferente de atuar com o Pensamento Matemático [Shute, Sun and Asbeel-Clarke 2017], bem como o Letramento Computacional e as Competências Digitais, embora existam intersecções e complementações entre as fundamentações [Valente 2019]. Neste sentido, para se difundir o PC é possível fazer uso de atividades plugadas, que requerem o uso do computador, ou desplugadas, que não o necessitam.

Apesar da existência dessas atividades, ainda não existe, no Brasil, a aplicação 
do PC como componente curricular na Educação Básica. Por esta razão, tem-se observado iniciativas de grupos de pesquisas para difundi-lo por meio da aplicação de projetos em sala de aula [Medeiros et al. 2018a]. Em outros contextos, existem diversas plataformas online, jogos e demais atividades que podem ser utilizadas para as crianças trabalharem o PC fora do ambiente escolar [Vicari et al. 2018].

No início de 2020, enquanto formas de inserir o PC em sala de aula continuavam sendo estudadas, a Organização Mundial da Saúde (OMS) decretou o estado de pandemia ${ }^{1}$ por causa do vírus Sars-Cov-2. Isto gerou uma recomendação de isolamento, distanciamento social, dentre outras ações que implicaram na suspensão das aulas presenciais, fazendo com que todas as áreas da sociedade tivessem que se adaptar ao chamado "novo normal". Neste sentido, o contexto de pandemia da COVID-19 requer esforços de diversas frentes, sendo uma delas a educacional, pois é necessário permitir que o sistema de educação continue funcionando, mesmo que parcialmente, através do desenvolvimento de atividades variadas. Por sua vez, estas atividades devem ter fundamentação pedagógica e permitir que as famílias façam uso dos materiais, sem para isso exigir tantos aparatos tecnológicos. Esse requisito se mostra bastante relevante na situação atual do Brasil que, devido as suas grandes desigualdades sociais, impede boa parte da população jovem das classes D e E de ter um acesso satisfatório aos computadores e à internet [CETIC 2020].

Portanto, é preciso oportunizar a aplicação de atividades diversas com as crianças, independentemente de classe social, para que elas continuem se desenvolvendo, mesmo estando privadas das escolas. Por isso, a elaboração de materiais contendo atividades para difundir o PC por meio de Computação Desplugada se mostram ideais [Tim, Bell and Wittens 2011]. No entanto, para que as crianças venham a se engajar com tais atividades, é fundamental que as mesmas sejam contextualizadas com o seu dia a dia, levando em conta os seus interesses e inquietações, de forma que realmente venham a motivá-las para a realização. Sem engajamento, dificilmente as crianças se empenharão com atividades extraescolares.

Visando contribuir neste sentido, o presente trabalho apresenta um modelo para construção de atividades desplugadas contextualizadas a fim de engajar as crianças no desenvolvimento das habilidades do PC. Esse modelo foi utilizado para desenvolver um Guia do Pensamento Computacional para as crianças de 6 a 11 anos, um material que permite que as crianças e os pais aprendam o que é PC, quais são as suas aplicações, e tenham ciência sobre as competências e habilidades que são desenvolvidas para fazer uso das mesmas em suas tarefas cotidianas.

O trabalho encontra-se dividido em cinco seções. Além desta introdução, a seção 2 se concentra em prover maiores detalhes dos projetos mencionados anteriormente que abordam trabalhos relacionados à proposta. A seção 3 descreve o modelo proposto para construção de atividades desplugadas contextualizadas, apresentando as etapas aplicadas para o desenvolvimento do guia do PC para as crianças. Os resultados obtidos com o uso do guia e suas respectivas discussões são tratados na seção 4. Por fim, a seção 5 dispõe sobre as considerações finais.

1 https://www.who.int/dg/speeches/detail/who-director-general-s-opening-remarks-at-the-mediabriefing-on-covid-19---11-march-2020. 


\section{Trabalhos Relacionados}

[Medeiros et al. 2018a] apresentam um modelo de proposta de ensino de Pensamento Computacional para públicos com conhecimentos e idades variadas para trabalhar com o ensino de algoritmos através de poemas fora do contexto da sala de aula. Como resultados, apontam que os participantes puderam criar, ler, interpretar poemas e transformá-los em algoritmos. Já [Medeiros et al. 2018b] descrevem um outro modelo para ensinar PC para crianças do $6^{\circ}$ ano do Ensino Fundamental de escolas públicas em contexto com baixa infraestrutura tecnológica laboratorial, para isso, fazem o uso de Computação desplugada. Como resultados, evidenciaram melhora na leitura e na produção de textos das crianças.

[França and Tedesco 2018] relatam um modelo para o desenvolvimento das habilidades de autorregulação e resolução de problemas dos estudantes para trabalhar com PC. Os resultados demonstraram que a estratégia é relevante para aprender PC e pode auxiliar no processo de autorregulação dos estudantes. [Silva, Melo and Tedesco 2018] descrevem um modelo gamificado para promover o engajamento estudantil e auxiliar o aprendizado de programação, para proporcionar um aprendizado personalizado. Como resultados, evidenciam recomendações e estratégias de aprendizagem para amenizar o problema. [Marques et al. 2017] desenvolveram um modelo conceitual para propor atividades matemáticas que impulsionam $o$ desenvolvimento de habilidades do PC. Como conclusões, evidenciam a facilidade de domínio e aplicação pelos professores e a integração das atividades com o currículo existente.

Os trabalhos relatados, apesar de possibilitarem a difusão da Ciência da Computação por meio do Pensamento Computacional, não expõem como construir materiais ou guias para trabalhar o PC com crianças em um contexto em que é mediado pelos pais e contextualizando com o seu cotidiano, tampouco permite que exista uma validação realizada pelos usuários permitindo uma evolução constante dos material e maior interação entre autores e público-alvo.

\section{Etapas do desenvolvimento de atividades desplugadas contextualizadas}

Conforme mencionado na Introdução, este trabalho propõe um modelo para construção de atividades desplugadas destinadas a crianças de 6 a 11 anos de idade. Na subseção a seguir, apresentaremos o modelo em si, e, na seguinte, a aplicação do modelo na construção do Guia de Pensamento Computacional.

\subsection{Modelo proposto}

O modelo de atividades proposto é formado por 4 etapas. Na etapa 1, encontra-se a descrição das diretrizes basilares definidas para a elaboração do material. Na etapa 2, acontece a construção do material, em que as diretrizes são consideradas para a definição das atividades e currículo, bem como é enviado o produto desenvolvido para o público-alvo testar. Na etapa 3, ocorre a construção e a aplicação dos questionários ou demais testes para possibilitar o design participativo com os usuários que utilizaram o material. Após este processo de validação, caso ainda existam considerações a serem feitas, este processo volta para a etapa 1, reiniciando-se o ciclo. Caso contrário, 
prossegue-se para a etapa 4, a de publicação do material, conforme Figura 1.

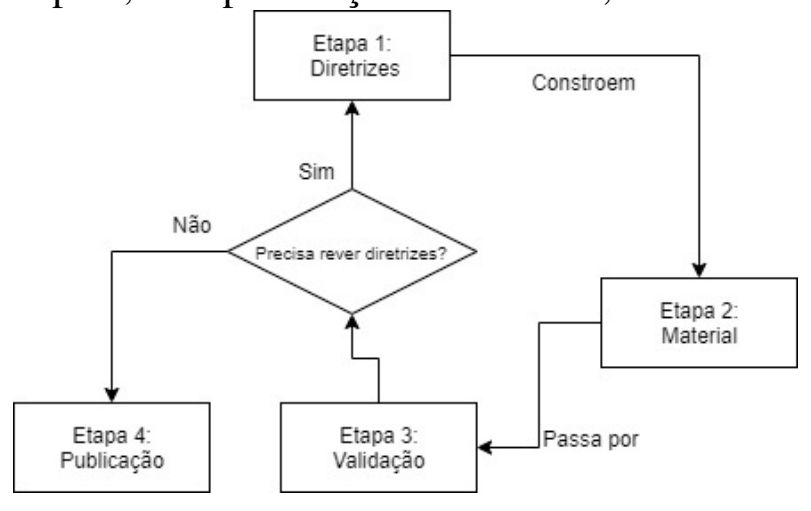

Figura 1. Representação gráfica do Modelo Fonte: os autores.

\subsection{Construção do Guia do Pensamento Computacional}

Para a construção do Guia do Pensamento Computacional foram consideradas três diretrizes que podem ser tomadas como basilares na construção de outros materiais, entretanto, não se limitam a elas para desenvolver o modelo, o que significa que outras podem ser inseridas na etapa 1 . Assim, a primeira diretriz delineada foi a Comunicável, adaptada da área de Interação Humano-Computador por meio das heurísticas de [Nielsen 1993], permitindo que a ferramenta, neste caso, o material, consiga gerar uma boa interação com o usuário através de sua usabilidade gerando o Engajamento Emocional em busca de evitar características como a ansiedade, o tédio, e a frustração e focando em gerar felicidade e interesse [Fredricks et al. 2004, Seixas, Melo and Gomes 2015].

Na segunda diretriz, denominada de Contexto do Público-alvo, é trabalhado o conceito de Pedagogia pela Experiência de [Dewey 1963] e a importância de atividades relacionadas ao Contexto para promover o interesse dos alunos pelas atividades [ Tissembaum et al. 2019]. Na terceira, Curriculos e práticas, analisa-se os currículos brasileiros existentes que mencionavam ou direcionavam de alguma forma como trabalhar o PC. Para tanto, investigou-se a Base Nacional Comum Curricular (BNCC), com foco nas Dez Competências Gerais, o currículo do Centro de Inovação para a Educação Brasileira (CIEB) e nas Diretrizes para o Ensino de Computação na Educação Básica da Sociedade Brasileira de Computação (SBC). Assim, também buscou-se Teorias da Aprendizagem que pudessem fundamentar o processo, para isso, baseou-se em características do Construcionismo elucidado por [Papert and Harel 1991], a Zona de Desenvolvimento Proximal (ZDP) descrita por [Vygotsky 1980], a Aprendizagem Ativa [Bonwell and Eison 1991, Moran 2013] e a Aprendizagem Significativa [Ausubel 1968].

Para tanto, a seguir, são descritos os aspectos práticos que se espera de cada diretriz:

1) Comunicável - espera-se que o material seja elaborado com uma linguagem acessível ao público-alvo, bem como transmita conceitos ou terminologias teóricas com assimilações a exemplos de ampla divulgação, sempre se colocando no lugar do 
usuário. O usuário não deve ser levado a se perder em muitos detalhes técnicos, portanto, a interface do material também deve ser a mais enxuta possível e minimalista. É necessário que exista uma seção para sanar possíveis dúvidas que surjam quando relacionadas à temática, a fim de desmistificar preconceitos e conflitos terminológicos.

2) Contexto do público alvo - devem ser trabalhados conteúdos e atividades, ou seja, se o público for variado, como para diferentes pessoas de distintas regiões do país, é necessário que o conteúdo seja direcionado. Se for para um público específico, é viável trabalhar questões que suscitem discutir sobre problemas locais ou culturais que remetam àquela população, nesse caso, trabalhar a educação libertária, como o Ciclo de Cultura de Paulo Freire.

3) Currículos e práticas - neste ponto deve-se mapear os currículos que discutem PC, bem como consultar as competências gerais da BNCC e como elas podem se relacionar com as atividades, que, por sua vez, devem propiciar momentos de descontração e ludicidade. Assim também deve permitir que a aprendizagem seja ativa por meio de metodologias que auxiliem essa execução de práticas, permitindo que o aluno se apoie em conceitos já concebidos.

Ao aplicar as diretrizes na produção do material, entra-se na etapa 2 do modelo. Por esta razão, para trabalhar a diretriz 1 foi criada uma seção com possíveis questionamentos sobre Pensamento Computacional ou conceitos correlatos que viessem a surgir no desenvolvimento das atividades, o que possibilita guiar quem estiver aplicando as atividades com as crianças. Nessa direção, foi utilizada uma linguagem mais coloquial e com utilização da primeira pessoa do plural (nós), a fim de que este espaço remetesse a uma interação entre o usuário e os desenvolvedores, conforme explicitado na Figura 2.

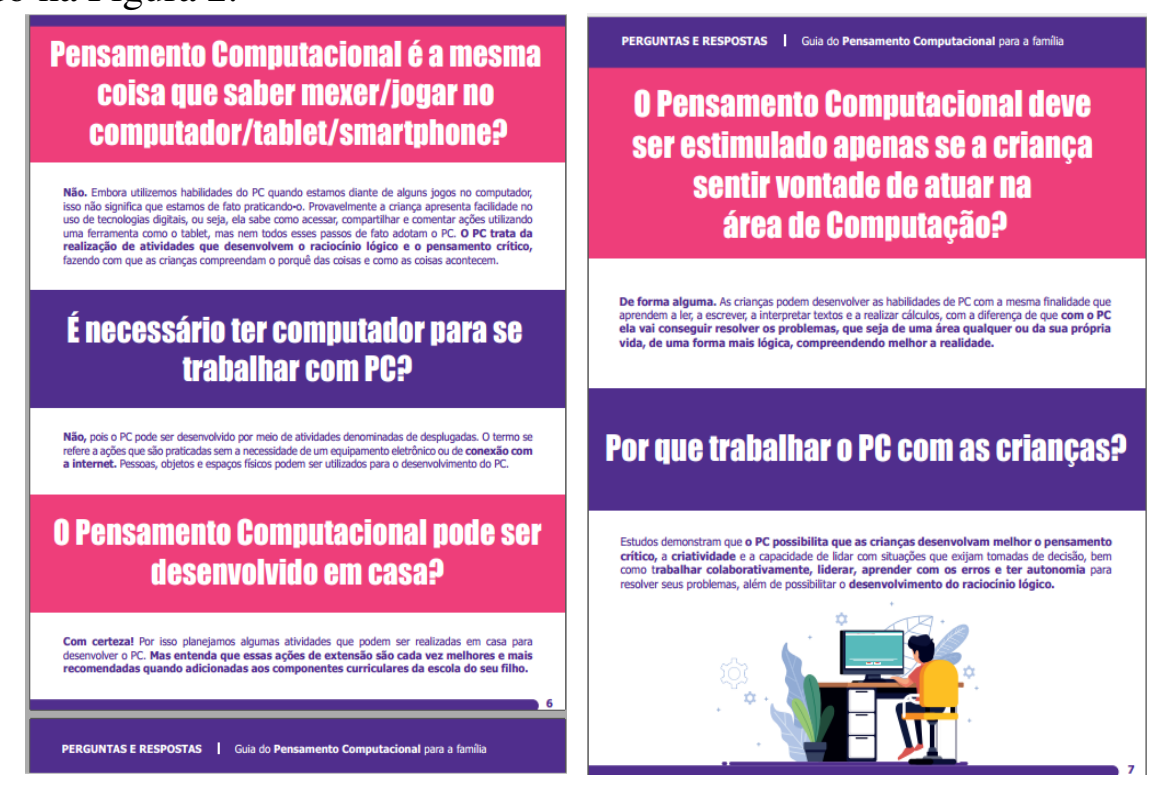

Figura 2. Seção de perguntas e respostas no Guia do Pensamento Computacional. Fonte: os autores.

O mesmo tipo de ação ocorreu durante a execução das atividades que, por sua vez, foram pensadas levando em consideração as diretrizes 2 e 3 . Nesse sentido, cada 
atividade foi elaborada tendo como norte as motivações descritas no Quadro 1. Salientase que em cada atividade foi considerada a aprendizagem ativa e significativa, posto que a criança se situa no centro do processo de ensino, construindo seu conhecimento e sendo mediada por um adulto por meio do auxílio do material, partindo de situações que já vivencia, passando da execução da Zona de Desenvolvimento Real para a Zona de Desenvolvimento Proximal.

\begin{tabular}{|c|c|l|}
\hline \multicolumn{2}{|c|}{ Atividade } & \multicolumn{1}{c|}{ Motivação } \\
\hline 1 & $\begin{array}{c}\text { Elaborando uma } \\
\text { festa de aniversário }\end{array}$ & $\begin{array}{l}\text { Retratar um acontecimento comum que uma criança já vivenciou, seja em sua vida ou } \\
\text { na de amigos, e que consiga fazer correlações com os pilares do PC, pois toda festa } \\
\text { possui características semelhantes, bem como exige a execução de passos lógicos. }\end{array}$ \\
\hline 2 & Álbuns da família & $\begin{array}{l}\text { Os álbuns permitem contar histórias de determinadas épocas, seja da própria criança } \\
\text { ou de outros membros da família, fazendo com que a criança se reconheça nesse } \\
\text { cenário e compreenda que existe um determinado padrão, por exemplo, em roupas } \\
\text { que permita identificar um determinado contexto histórico. Assim, permite que a } \\
\text { criança estabeleça mais laços afetivos com a sua cultura e parentes. }\end{array}$ \\
\hline 3 & $\begin{array}{c}\text { Compras no } \\
\text { supermercado }\end{array}$ & $\begin{array}{l}\text { Por ser uma atividade que é realizada rotineiramente, e principalmente neste período } \\
\text { de pandemia, ganhou mais ênfase para as crianças, pois elas estão mais tempo em } \\
\text { casa, logo, podem ajudar seus pais a fazerem a lista de compras, bem como } \\
\text { guardarem os produtos, organizando-os de acordo com as suas características e } \\
\text { observando como se comporta o processo de abstração. }\end{array}$ \\
\hline 4 & $\begin{array}{c}\text { Sintomas da COVID- } \\
19\end{array}$ & $\begin{array}{l}\text { Devido a doença ser o motivo das crianças estarem em casa, utilizar os sintomas } \\
\text { dessa enfermidade para trabalhar o pilar reconhecimento de padrões é uma das } \\
\text { alternativas encontradas para associar a atividade ao contexto. }\end{array}$ \\
\hline 5 & $\begin{array}{c}\text { Cálculo de uma } \\
\text { conta armada de } \\
\text { somar }\end{array}$ & $\begin{array}{l}\text { Para que as crianças percebam que o PC já faz parte do seu cotidiano na sala de aula, } \\
\text { nesta atividade são evidenciados todos os passos por trás da execução de uma conta } \\
\text { de somar. Assim, ela perceberá que ao desenvolver esse tipo de atividade, pode-se } \\
\text { quebrar em etapas menores para se chegar ao resultado final }\end{array}$ \\
\hline 6 & $\begin{array}{c}\text { Desenvolvendo } \\
\text { receitas }\end{array}$ & $\begin{array}{l}\text { Buscou-se uma forma mais ampla e comum de se representar algoritmos, como } \\
\text { também fazer com que as crianças participem do processo criativo de criar um prato. }\end{array}$ \\
\hline
\end{tabular}

Quadro 1. Descrição das atividades e motivações do Guia de PC. Fonte: os autores.

A sintetização das atividades associadas aos pilares do Pensamento Computacional, bem como quais as Competências Gerais da BNCC escolhidas, das dez existentes, estão representadas na Figura 3. A escolha por determinadas CGs se justifica pela diretriz 3 e o tipo de atividade desenvolvida.

\begin{tabular}{|c|c|c|c|c|c|}
\hline \multirow{2}{*}{ Atividade } & \multicolumn{4}{|c|}{ Pilares do Pensamento Computacional } & \multirow{2}{*}{$\begin{array}{l}\text { Competências gerais da } \\
\text { BNCC }\end{array}$} \\
\hline & Abstração & Decomposição & Padrões & Algoritmos & \\
\hline $\begin{array}{c}\text { Elaborando uma } \\
\text { festa de aniversário }\end{array}$ & $\mathrm{x}$ & $\mathrm{x}$ & $\mathrm{x}$ & $\mathrm{x}$ & [CG9][CG7] \\
\hline $\begin{array}{l}\text { Separar os } \\
\text { brinquedos }\end{array}$ & $\mathrm{x}$ & & $\mathrm{x}$ & & [CG2][CG10] \\
\hline $\begin{array}{c}\text { Compras no } \\
\text { supermercado }\end{array}$ & $\mathrm{x}$ & & $\mathrm{x}$ & & [CG1][CG9] \\
\hline $\begin{array}{l}\text { Sintomas da } \\
\text { COVID-19 }\end{array}$ & & & $\mathrm{x}$ & & $\begin{array}{c}\text { [CG2] [CG1] } \\
\text { [CG7] }\end{array}$ \\
\hline $\begin{array}{l}\text { Cálculo de uma conta } \\
\text { armada de somar }\end{array}$ & $\mathrm{x}$ & $\mathrm{x}$ & $\mathrm{x}$ & $\mathrm{x}$ & $\begin{array}{r}{[\mathrm{CG} 2]} \\
{[\mathrm{G} 1]}\end{array}$ \\
\hline $\begin{array}{l}\text { Desenvolvendo } \\
\text { receitas }\end{array}$ & $\mathrm{x}$ & $\mathrm{x}$ & $\mathrm{x}$ & $\mathrm{x}$ & $\begin{array}{c}\text { [CG2] [CG9] } \\
{[\text { CG4] }}\end{array}$ \\
\hline
\end{tabular}

Figura 3. Atividades, pilares do PC e CG da BNCC utilizadas na elaboração do Guia. Fonte: os autores. 
Finalizada a etapa do material, iniciou-se a etapa de validação. Para desenvolvêla foi elaborado um formulário, disponível em formato de link ao final do Guia, utilizando o Google Forms, a fim de que quem executasse as atividades com as crianças pudesse respondê-lo. O formulário é composto por 7 questões dissertativas e de escolha binária, que visam trabalhar com o Design Participativo, discutido por [Schuler and Namioka 1993]. De maneira geral, buscou-se validar a proposta de elaboração do material a fim de que pudesse ao analisá-lo prosseguir para a etapa 4, a evolução do material. Os resultados dessa validação encontram-se dispostos na seção 4.

\section{Resultados e discussões}

O Guia produzido está disponível em [OMITIDO PARA AVALIAÇÃO] ${ }^{2}$, e foi amplamente divulgado nas redes sociais. Não foi possível mensurar a quantidade de pessoas que tiveram acesso ao material, assim como não foi tomado como obrigatório o preenchimento do formulário de avaliação. Apesar disso, foi contabilizado que 23 pessoas responderam ao formulário. A primeira questão tinha como objetivo entender se o Conceito "Pensamento Computacional" tinha ficado claro para quem aplicou com as crianças. Nesse item, 100\% das pessoas responderam "sim". Na segunda pergunta, buscou-se compreender se quem aplicou a proposta conseguiu entender o que significava os Pilares do Pensamento Computacional. Nessa direção, 95,7\% disseram "sim" e 4,3\% disseram "não". Ainda, buscou-se validar a seção de perguntas e respostas que foram adicionadas antes das atividades com estas duas primeiras questões. $\mathrm{O}$ resultado obtido apresenta boas avaliações pelo público participante, o que direciona a inserir em uma nova versão, fazendo uso de algumas outras adaptações a serem estudadas.

Na terceira pergunta, indagou-se: "Você sentiu dificuldade para executar alguma atividade com a criança?". 87\% disseram "não" e 13\% "sim". Como pergunta complementar, questionou-se: "Se você respondeu sim à questão anterior, argumente o motivo". Assim, foram obtidas as seguintes respostas: "Pressupõe um adulto alfabetizado para acompanhar a criança"; "Adequar a outras faixas etárias" e "Saber si entendem ou não". Verificou-se, por meio destas respostas, que se pode continuar aplicando as atividades seguindo a mesma perspectiva de trabalhar com o cotidiano. Ainda assim, é salutar que se torne mais inclusivo, para atingir pais que não são alfabetizados, por exemplo.

$\mathrm{Na}$ quarta pergunta, questionou-se: "Você sentiu dificuldade para elaborar a atividade 7?". A atividade 7 dizia respeito à elaboração de uma nova atividade sobre PC, tomando como exemplo as anteriores. A essa indagação, 100\% respondeu "não". Isso comprova que as atividades anteriores direcionaram os participantes para saberem reproduzir a temática $\mathrm{PC}$ com outras atividades elaboradas por eles próprios, bem como que o Construcionismo (Papert 1980) presente nas atividades do Guia possibilitou que o conhecimento fosse construído durante a execução delas.

$\mathrm{Na}$ quinta pergunta, a saber: "A criança se sentiu empolgada ao praticar as atividades?", 82,6\% afirmaram "sim" e 17,4\% "não". Isto aponta que trabalhar com atividades do cotidiano faz com que o aluno se sinta empolgado e engajado, tal como

2 https://sorayaroberta.github.io/guia.pdf 
afirma [Tissenbaum et al. 2019]. Na sexta pergunta, questionou-se: "Se a criança fosse executar outra atividade cotidiana que necessitasse dos conhecimentos que foram expostos no Guia, você acredita que ela conseguiria aplicar o PC?". Como respostas, 91,3\% afirmaram "sim" e 8,7\% "não". Perguntou-se, então, o porquê da criança não saber aplicar, em caso da resposta "não". Como respostas: "Criança não compreende fácil, metodologia informativa, mas responde bem.", "Inicialmente acredito que sim, pois essa foi a primeira experiência dele". Tais respostas levam para um cenário de revisão do tipo de linguagem presente no material, uma vez que se utilizou do enfoque instrucional.

Na sétima questão, "Você recomendaria este Guia para as pessoas próximas?", $100 \%$ responderam "sim". Na oitava questão, questionou-se se o Guia proporcionou momentos de descontração entre a família. Nesse sentido, 87\% afirmaram "sim" e 13\%, "não". Por fim, foi aberto um espaço para os participantes deixarem comentários sobre a proposta, dos quais destacam-se os seguintes: "Em uma nova versão do guia podem ser acrescentados atividades com fluxogramas", "Sugerir escritas de listas de palavras do campo semântico da atividade", "Poderá incluir atividades que relacionem conhecimentos transversais. Obrigada!",Jogos visuais, interativos com crianças com necessidades especiais."

Sobre as críticas, os participantes apontaram sugestões, entre as quais, destacamse: inserir mais atividades; fazer a correção ortográfica; ampliar o formulário para questões além de sim e não; criar "Um canal com mais dicas e maior divulgação", ressaltando que era uma temática "Muito pertinente para o momento que vivemos"; e também parabenizaram pelo elaboração do Guia de PC. Estas sugestões evidenciam a necessidade de realizar entrevistas com stakeholders tais como o público-alvo para construir um Design Participativo [Schuler and Namioka 1993] a fim de ter a elaboração de um produto mais consistente e mais coeso com a realidade em que vai ser inserido. Além desse formulário, professores enviaram mensagens para os pesquisadores e enfatizaram que elaboraram a proposta em outros espaços, e, ainda, que iriam utilizar o material em turmas para que os pais pudessem trabalhar em casa com as crianças.

\section{Considerações finais}

Neste trabalho foi proposto um modelo de desenvolvimento de atividades desplugadas para se trabalhar PC com crianças de 6 a 11 anos. Como aplicação, foi desenvolvido uma Guia do Pensamento Computacional. O feedback gerado pelas pessoas que avaliaram o Guia demonstra que o seu desenvolvimento atende às diretrizes, que abrange de forma adequada os pilares do PC e que engaja as crianças e faz elas aprendem o PC.

Por outro lado, faz-se necessário ampliar as diretrizes, inserindo conceituações referentes à educação especial e inclusiva, bem como ampliar a validação para um questionário utilizando escala de Likert. Assim também, deixar mais claro aspectos como engajamento para quem for responder o questionário, bem como, desenvolver uma seção no Guia que apresente como os pais ou responsáveis podem ajudar a avaliar a aprendizagem da criança. Com relação às etapas do modelo, o Guia voltará à etapa 1 para se adaptar às diretrizes que surgiram com a validação, para, posteriormente, 
IX Congresso Brasileiro de Informática na Educação (CBIE 2020)

Anais do XXXI Simpósio Brasileiro de Informática na Educação (SBIE 2020)

desenvolver mais atividades e validá-las com o público-alvo por meio da elaboração de outro questionário.

\section{Referências}

Ausubel, D. (1968). Educational Psychology: a cognitive view. New York: Holt, Rinehert end Winston.

Brasil. Base Nacional Comum Curricular: Educação é a base. (2017). Disponível: http://basenacionalcomum.mec.gov.br/. Acesso em: 16 jun. 2020.

Bonwell, C. C. and Eison, J. A. (1991). Active Learning: Creating Excitement in the Classroom. ASHE-ERIC Higher Education Reports.

CETIC.BR, 2020. TIC por domicílios em 2019. Disponível em: https://cetic.br/media/analises/tic_domicilios_2019_coletiva_imprensa.pdf. Acesso em: 26 junho 2020.

Dewey, John. Experience and Education (1963[1938]; repr.). New York.

De França, Rozelma Soares; TEDESCO, Patrícia Cabral de Azevedo Restelli. (2014). Um modelo colaborativo para a aprendizagem do pensamento computacional aliado à autorregulação. Brazilian Symposium on Computers in Education (Simpósio Brasileiro de Informática na Educação - SBIE), [S.1.], p. 1133, nov. 2014. ISSN 2316-6533. Disponível em: https://brie.org/pub/index.php/sbie/article/view/3059/2567. Acesso em: 01 ago. 2020. doi:http://dx.doi.org/10.5753/cbie.sbie.2014.1133.

Fredricks, J. A., Blumenfeld, P. C., \& Paris, A. H. (2004). School engagement: Potential of the concept, state of the evidence. Review of educational research, 74(1), 59-109. doi: 10.3102/00346543074001059.

Marques, Monica et al. (2017).Uma Proposta para o Desenvolvimento do Pensamento Computacional Integrado ao Ensino de Matemática. Brazilian Symposium on Computers in Education (Simpósio Brasileiro de Informática na Educação - SBIE), [S.1.], p. 314, out. ISSN 2316-6533. Disponível em: https://brie.org/pub/index.php/sbie/article/view/7560/5356. Acesso em: 02 ago. 2020. doi:http://dx.doi.org/10.5753/cbie.sbie.2017.314.

Medeiros, Soraya et al. (2018a). Ensino de algoritmos através de Poesia Compilada e Computação Desplugada: Relato de experiência com alunos de Ensino Fundamental. Anais do Workshop de Informática na Escola, [S.1.], p. 381, out. ISSN 2316-6541. Disponível em: https://br-ie.org/pub/index.php/wie/article/view/7907. Acesso em: 17 jul. 2020. doi:http://dx.doi.org/10.5753/cbie.wie.2018.381.

Medeiros, S., Rabelo, H., Nunes, I., Garcia, T., Medeiros, F., Rabelo, D., \& Medeiros, A. (2018). Ensino de algoritmos com poemas através do editor Poesia(): Relato de experiência . Anais dos Workshops do Congresso Brasileiro de Informática na Educação, 7(1), 341. doi:http://dx.doi.org/10.5753/cbie.wcbie.2018.341

Moran, J. (2013).Metodologias ativas para uma aprendizagem mais profunda,. Disponívelem:http://www2.eca.usp.br/moran/wpcontent/uploads/2013/12/metodolog ias_moran1.pdf. Acesso em: 5 maio 2020. 
Papert, S.; Harel, I. (1991). Constructionism.USA: Ablex Publishing Corporation.

Cieb, Currículo de Tecnologias e Computação. 2018. Disponível em: https://curriculo.cieb.net.br/curriculo. Acesso em: 2 Ago. 2020.

Santos, José Amancio et al. (2019). Pensamento computacional para alunos do ensino fundamental de escolas públicas em uma cidade de pequeno porte - um relato e análise de experiência. Anais do Workshop de Informática na Escola, [S.1.], p. 296, nov. ISSN 2316-6541. Disponível em: https://brie.org/pub/index.php/wie/article/view/8516/6089. Acesso em: 16 jul. 2020. doi:http://dx.doi.org/10.5753/cbie.wie.2019.296.

Seixa, L., de Melo Filho, I. J., \& Gomes, A. S. (2015). Identifying engagement indicators to support educational research. In Information Systems and Technologies (CISTI), 2015 10th Iberian Conference on (pp. 1-6). IEEE. doi: 10.1109/CISTI.2015.7170357

Silva, Tatyane Souza Calixto da; MELO, Jeane Cecília Bezerra de; TEDESCO, Patricia Cabral de Azevedo Restelli. (2018). Um Modelo para Promover o Engajamento Estudantil no Aprendizado de Programação Utilizando Gamification. Revista Brasileira de Informática na Educação, [S.1.], v. 26, n. 03, p. 120, set. ISSN 23176121. Disponível em: https://br-ie.org/pub/index.php/rbie/article/view/7116/6024. Acesso em: 01 ago. 2020.

SBC, Diretrizes para o ensino de computação na educação básica. 2018. Disponível em: https://www.sbc.org.br/documentos-da-sbc/send/203-educacao-basica/1220-bnccem-itinerario-informativo-computacao-2. Acesso em 11 junho 2020.

Schuler, Douglas; NAMIOKA, Aki (Ed.) 91993). Participatory design: Principles and practices. CRC Press.

Valente, José Armando. (2019). Pensamento Computacional, Letramento Computacional ou Competência Digital? Novos desafios da educação. Revista Educação e Cultura Contemporânea, v. 16, n. 43, p. 147-168.

Vicari, Rosa Maria; MOREIRA, Alvaro Freitas; MENEZES, Paulo Fernando Blauth (2018). Pensamento computacional: revisão bibliográfica.

Wing, Jeannette M. (2006). Computational thinking. Communications of the ACM, v. 49, n. 3, p. 33-35. 